\title{
Whole-grain intake of British young people aged 4-18 years
}

\author{
C. W. Thane ${ }^{1 *}$, A. R. Jones ${ }^{2}$, A. M. Stephen ${ }^{1}$, C. J. Seal ${ }^{2}$ and S. A. Jebb ${ }^{1}$ \\ ${ }^{1}$ MRC Human Nutrition Research, Elsie Widdowson Laboratory, Fulbourn Road, Cambridge CB1 9NL, UK \\ ${ }^{2}$ Human Nutrition Research Centre, School of Agriculture, Food \& Rural Development, University of Newcastle, Newcastle upon Tyne \\ $N E 17 R U, U K$
}

(Received 21 January 2005 - Revised 17 June 2005 - Accepted 20 June 2005)

\begin{abstract}
Inverse associations between whole-grain food consumption and risk of CVD, some cancers and type 2 diabetes have been reported. However, there are few reports of whole-grain intake, particularly among young people. The objective of the present study was to estimate whole-grain intake in a nationally representative sample of young people aged 4-18 years living in Great Britain. Whole-grain intake was estimated using $7 \mathrm{~d}$ weighed dietary records from 1583 young people who participated in the cross-sectional National Diet and Nutrition Survey in 1997. Whole-grain intake was quantified from the consumption of all foods containing $\geq 10 \%$ whole-grain content. Median whole-grain intake was $7 \mathrm{~g} / \mathrm{d}$ (interquartile range $0-19 \mathrm{~g} / \mathrm{d}$ ), with a corresponding mean of 13 (SD18) g/d. Intake was significantly lower among young people whose head of household had a manual occupation, but did not differ significantly by sex, age, region or season. There was no whole-grain intake for $27 \%$ of participants. The percentages for less than one and less than three $16 \mathrm{~g}$ amounts of wholegrain intake per d were 70 and 94, respectively, while corresponding percentages based on 20 g amounts were 76 and 97 . Foods with $<51 \%$ whole-grain content provided $28 \%$ of whole-grain intake overall, with a higher percentage in older adolescents. The main sources of whole-grain intake were breakfast cereals $(56 \%)$ and bread $(25 \%)$. The present study provides the first quantification of absolute whole-grain intake from all significant food sources in any representative age group in the UK. Although there is some debate regarding the quantity of whole grains required for good health, whole-grain intake among British young people is low.
\end{abstract}

Whole grain: Intake and food sources: Children: Great Britain

Epidemiological evidence suggests an inverse association between the consumption of whole-grain foods and the risk of premature all-cause mortality (Jacobs et al. 1999, 2001) and various chronic diseases. Prospective studies have found that habitual consumption of whole-grain foods is associated with reduced risk of some (mainly gastro-intestinal) types of cancer (Jacobs et al. 1998, 1999, 2001), CVD (Anderson, 2003; Jacobs \& Gallaher, 2004; Jensen et al. 2004) and type 2 diabetes (Venn \& Mann, 2004). Whole-grain food consumption has also been associated with lower body weight in middle-aged women compared with those who consumed more refined-grain foods (Liu et al. 2003).

The precise mechanisms by which whole grains exert their purported health benefits are unclear. Potentially health-promoting components of the bran, endosperm and germ fractions of whole grains include high amounts of dietary fibre (insoluble and soluble types, depending on the grain), vitamin $\mathrm{E}$ and a range of $\mathrm{B}$ vitamins, a variety of minerals such as $\mathrm{Fe}, \mathrm{Zn}$ and $\mathrm{Se}$, and a range of phytochemicals (Slavin, 2003). Similar to the situation with fruit and vegetables, the multitude of nutrients and phytochemicals in whole grains may act synergistically to exert a greater benefit to health from the 'whole package' than might be achieved from the sum of the individual components.

There are currently few reports in the literature of whole-grain intake, particularly for young people. With the exception of a recent report of absolute whole-grain intake in a large cohort of
American adults (Jensen et al. 2004), a notable epidemiological study based in Norway (Jacobs et al. 2001) and a previous estimate in British adults (Lang et al. 2003), most estimates have reported either numbers of servings (Cleveland et al. 2000; Kantor et al. 2001; Harnack et al. 2003) or eating occasions (Albertson \& Tobelmann, 1995) of whole-grain-containing foods. Expressing intake in absolute terms provides a more precise quantification of wholegrain intake and will provide a more robust platform from which to consider diet-disease associations.

The aim of the present study was to quantify absolute intake and all significant food sources of whole grains among young people living in Great Britain, using data from the National Diet and Nutrition Survey (NDNS) of young people aged 4-18 years (Gregory et al. 2000). This is particularly pertinent given the increasing awareness of the importance of childhood diet as a predictor of long-term health outcomes.

\section{Subjects and methods}

Survey

The NDNS of young people aged 4-18 years (Gregory et al. 2000) was conducted between January and December 1997. It collected dietary, biochemical, socio-economic and lifestyle data from a nationally representative random sample of 2127 participants 
living in mainland England, Scotland and Wales. Ethical approval for all procedures was granted by Local Research Ethics Committees for each of the postcode sectors included in the survey. Full details of dietary methodology and all aspects of the survey are provided in the survey report (Gregory et al. 2000).

Participants ( $n 1699,80 \%$ of the interview sample) completed $7 \mathrm{~d}$ weighed dietary records to assess food consumed both inside and outside the home. The completer of the dietary record depended on the age and ability of the young person. Of these records, 1583 food diaries were analysed for the estimation of whole-grain intake in participants who also provided information for each of the assessed socio-demographic factors. Factors examined were sex (boys, girls), age group (4-6, 7-10, 11-14, 15-18 years), region (Scotland, North, Midlands, East Anglia, Wales, South West, London and South East), occupational social class of head of household (non-manual, manual) and season (Winter, January to March; Spring, April to June; Summer, July to September; Autumn, October to December). Categories for occupational social class of head of household were derived from standard categories used in the Registrar General's Standard Occupational Classification (Great Britain Office of Population Censuses and Surveys, 1991). 'Non-manual' corresponded to social classes I, II and IIInm (professional, managerial, technical and skilled non-manual occupations), while 'manual' corresponded to social classes IIIm, IV and V (skilled manual, partly skilled and unskilled occupations).

The representativeness of findings from young people included in the current analysis ( $n$ 1583) was assessed by comparing their socio-demographic and lifestyle characteristics with those of young people who participated in the interview sample but who did not provide the necessary dietary records and socio-demographic/lifestyle information ( $n$ 544). Data have not been weighted to take into account slight differences in the age-sex distribution of responders and non-responders since the impact of this adjustment, applied as a weighting factor, for other dietary components measured in this cohort and reported by Gregory et al. (2000) was very small and not significant.

\section{Estimating whole-grain intake}

From over 4000 foods consumed by the entire sample, 151 were identified within the dataset as containing at least $10 \%$ wholegrain content (on a dry weight basis) as a percentage of the fresh weight of food. Whole grains considered in the present study include whole wheat, wholemeal flour, wheat flakes, bulgar wheat, whole and rolled oats, oatmeal, oat flakes, oat flour, brown rice, wholemeal rye and rye flour, whole barley and popcorn. Cornmeal was not included as a whole-grain ingredient since it is usually de-hulled, de-branned and de-germed. Foods containing high amounts of bran, but being deficient in either or both of the other two components of whole grains (endosperm and germ), were not included as whole-grain foods. Sweetcorn was also not included as a whole-grain food in the present study since in the NDNS it was coded as a vegetable rather than a grain.

Whole-grain intake was estimated by assigning individual whole-grain contents to each food identified from the dataset, through the use of recipes and ingredient information. These were obtained either from different editions and supplements of McCance and Widdowson's The Composition of Foods (Paul \& Southgate, 1985; Holland et al. 1988, 1991; Food Standards Agency, 2002), from the manufacturers (particularly for breakfast cereals), or calculated from a specialist recipe book for cakes and baked cereal products (Hobson, 2002). Weight losses of foods from processing were taken into account when estimating percentage of whole-grain content.

Whole-grain-containing foods were also categorised as containing low, medium and high percentages of whole grains, corresponding to 10 to $<25,25$ to $<51$, and $\geq 51 \%$ whole-grain content. The variation in the contribution to whole-grain intake from foods containing these three ranges of whole-grain content was then assessed according to the different socio-demographic factors.

The method for quantifying absolute intakes of whole grains was used in preference to identifying each consumption occurrence of a whole-grain food (with $\geq 51 \%$ whole-grain content only). This latter approach, used in a previous analysis of whole-grain food consumption in British adults (Lang et al. 2003), does not take into account serving size and fails to consider the contribution of foods containing $<51 \%$ whole-grain content. Although $51 \%$ whole-grain content is a useful cut-off point for labelling and for the purposes of health claims (Richardson, 2003), foods containing a smaller percentage may be consumed in sufficient amounts to make a significant contribution to total whole-grain intake.

Averages and distributions of whole-grain intake are reported in $\mathrm{g} / \mathrm{d}$ and sub-divided by the selected socio-demographic factors. Whole-grain intake is also reported in relation to 16 and $20 \mathrm{~g}$ amounts: $16 \mathrm{~g}$ amounts have been suggested in the USA (derived from the Food Guide Pyramid servings database, available at http://www.ba.ars.usda.gov/cnrg/services/flarchive.html) while a $20 \mathrm{~g}$ amount has been suggested in the UK (Smith et al. in press). Assuming a whole-grain content of around $50 \%, 20 \mathrm{~g}$ of whole grains is closer to the amount in typical serving sizes of breakfast cereals consumed by young people in the NDNS. Among adults living in the Newcastle upon Tyne area of northern England, mean serving sizes of two types of breakfast cereal were in the range $33-(53 \mathrm{~g}$, while those for wholemeal bread were around $80 \mathrm{~g}$ (Jones et al. 2003), thus representing two servings.

Percentage contribution of food groups to whole-grain intake was also determined, in boys and girls together and separately, according to the selected socio-demographic factors. Consumption, and non-consumption, of whole-grain-containing breakfast cereals and wholemeal bread was also assessed.

\section{Statistical analysis}

Food consumption data were collated and analysed using Excel (Microsoft Corp., Redmond, WA, USA) and SPSS (SPSS Inc., Chicago, IL, USA) software programs. The variation in wholegrain intake (daily averages and distributions, and percentages of participants consuming below 16 or $20 \mathrm{~g}$ amounts per d) was assessed by sex, age group, occupational social class of the head of household, region and season.

When the frequency distributions of continuous data were nonnormally distributed, non-parametric statistical tests were performed, with the best average provided by the median and spread of values given by the interquartile range (IQR; representing the central $50 \%$ of the distribution). The arithmetic mean with standard deviation or $95 \% \mathrm{CI}$ is also provided for comparison.

For each factor, category differences in whole-grain intake were determined using the Mann-Whitney $U$ and KruskalWallis $H$ tests for two- and multi-level factors, respectively. In the USA, individuals with energy requirements of at least $1600 \mathrm{kcal} / \mathrm{d}$ (equivalent to $6.7 \mathrm{MJ} / \mathrm{d}$ ) have been recommended to 
consume at least three 1-ounce $(28 \mathrm{~g})$ servings of whole-grain foods/d (US Department of Health and Human Services and US Department of Agriculture, 2005). Therefore, percentages of young people consuming less than three $(<3)$ as well as zero and less than one $(<1)$ daily 16 and $20 \mathrm{~g}$ amounts of wholegrain intake were also determined, along with their variation according to the five socio-demographic factors. This was determined by considering all foods containing $\geq 10 \%$ whole-grain content as well as those containing $\geq 51 \%$. Univariate analyses were conducted using the $\chi^{2}$ test, with multiple logistic regressions also conducted - to adjust for possible confounding effects of the other factors.

Results are presented using data from the entire sample. However, statistical analyses were also performed after excluding participants who reported (or were reported by their parents or guardians, depending on the age and ability of the young person) being unwell with eating habits affected on any day during the period of dietary assessment $(163 / 1583,10 \%$ of the total). The effect of likely under-reporting of food consumption was also considered, albeit rather crudely, by additional exclusion of participants for whom the ratio of recorded energy intake to estimated BMR (Schofield et al. 1985) was below a cut-off point of 1.2 (Goldberg et al. 1991). Following this additional exclusion, data were analysed for 1073 participants. Throughout all of the analyses, $P<0.05$ was used to denote statistical significance.

\section{Results}

The percentage of boys and girls among the 1583 young people included in the current analysis ( $51 \% v .49 \%)$ were almost identical to those who did not provide a dietary record or the necessary socio-demographic and lifestyle information ( $52 \%$ v. $48 \%)$. However, those excluded from the current analysis were significantly more likely to come from a family where the head of household had a manual versus non-manual occupation (59\% v. $49 \%$, $P<0 \cdot 001)$. A higher percentage of young people aged 15-18 years were excluded than from other age groups $(P<0 \cdot 001)$.

\section{Whole-grain intake}

Median whole-grain intake for the entire sample in $\mathrm{g} / \mathrm{d}$ was 7 (IQR $0-19$ ); boys 7 (IQR 0-21), girls 6 (IQR 0-17). Corresponding mean values were 13 (SD 18) $\mathrm{g} / \mathrm{d}$ for the entire sample; 15 (SD19) and $12(\mathrm{SD} 16) \mathrm{g} / \mathrm{d}$ for boys and girls, respectively. Whole-grain intake ranged from 0 to $163 \mathrm{~g} / \mathrm{d}$, with $95 \%$ of values between 0 and 66 (0-71 and $0-58 \mathrm{~g} / \mathrm{d}$ for boys and girls, respectively).

Whole-grain intake did not differ significantly by sex, age group, region or season although young people whose head of household had a manual occupation had lower whole-grain intake than those with a non-manual occupation [5 (IQR 0-17) v. 8 (IQR $1-21) \mathrm{g} / \mathrm{d}, P<0 \cdot 001]$. After excluding likely underreporters, the difference only remained significant in girls.

When only foods containing $\geq 51 \%$ whole-grain content were considered, the median whole-grain intake for the entire sample in g/d was 4 (IQR 0-15); boys 5 (IQR 0-17), girls 4 (IQR 0-14). Median whole-grain intake was again lower in those whose head of household had a manual versus non-manual occupation [3 (IQR 0-14) v. 6 (IQR 0-17) g/d, $P=0.003$ ], although this was no longer significant after excluding likely under-reporters [4 (IQR 0-14) v. 5 (IQR 0-18) g/d, $P=0 \cdot 10]$. Median wholegrain intake was also lower for younger age groups, although this was only statistically significant for boys (after adjustment for possible confounding from the other socio-demographic factors, $P=0.03$ ), even after excluding likely under-reporters.

When foods with $\geq 10 \%$ whole-grain content were considered, $70 \%$ and $94 \%$ of the entire sample had $<1$ and $<316 \mathrm{~g}$ amounts of whole-grain intake per $\mathrm{d}$, respectively. These percentages became 76 and 96, respectively, when considering only foods with $\geq 51 \%$ whole-grain content. The percentages for the entire sample and their variation by selected socio-demographic factors are shown in Table 1.

In terms of $20 \mathrm{~g}$ amounts of whole grains, $76 \%$ and $97 \%$ of the entire sample had $<1$ and $<320 \mathrm{~g}$ amounts of whole-grain intake per d, respectively. These percentages became $82 \%$ and $98 \%$, respectively, when considering only foods with $\geq 51 \%$ wholegrain content. Similar to values based on $16 \mathrm{~g}$ amounts of whole grains, these percentages were altered only negligibly after excluding those who reported being unwell with eating habits affected or after additional exclusion of likely under-reporters.

Girls were significantly more likely than boys to have intakes $<1$ and $<316$ and $20 \mathrm{~g}$ amounts of whole grains. In contrast, the percentages of young people with whole-grain intakes $<1$ and $<316 \mathrm{~g}$ amounts per $\mathrm{d}$ did not differ significantly with age, either before or after excluding those who reported being unwell with eating habits affected or likely under-reporters. Results were similar when only foods with $\geq 51 \%$ whole-grain content were considered and when the amount of whole grains was $20 \mathrm{~g}$. The present findings applied to both boys and girls.

The percentages of young people with $<1$ and $<316 \mathrm{~g}$ amounts of whole-grain intake per $\mathrm{d}$ also varied with occupational social class of the head of household (each $P<0 \cdot 05$ ), independent of the other socio-demographic factors. The percentage of young people who reported consuming $<116 \mathrm{~g}$ (and $20 \mathrm{~g}$ ) amounts of whole grain per $d$ was significantly higher when their head of household had a manual occupation. However, these differences were no longer statistically significant after excluding likely under-reporters. Differences by occupational social class of the head of household were also attenuated when only foods containing $\geq 51 \%$ whole-grain content were considered.

\section{Sources of whole-grain intake}

Overall, breakfast cereals provided more than one-half (56\%) and breads one-quarter (of which wholemeal bread provided $21 \%$ ) of whole-grain intake. Biscuits provided $9 \%$ of whole-grain intake, with the remaining contributions obtained from a variety of sources (Fig. 1).

Foods with $\geq 51 \%$ whole-grain content contributed $72 \%(95 \%$ CI 70, 74) of whole-grain intake overall. Foods with 25 to $<51 \%$ whole-grain content contributed $13 \%(95 \%$ CI 11,15$)$ to wholegrain intake, with the remainder contributed by those containing 10 to $<25 \%$ whole-grain content. The percentage of wholegrain intake contributed by foods with $\geq 51 \%$ whole-grain content fell significantly with age, from $78 \%$ in those aged $4-6$ years to $69 \%$ in those aged $15-18$ years. Around $90 \%$ of whole-grain intake was in the form of wheat as opposed to other cereal grains such as oats and rye.

The contribution of breakfast cereals to whole-grain intake differed significantly with age. Young people aged 15-18 years derived substantially less of their whole-grain intake from breakfast cereals than those aged 4-14 years (48\% v. 57-62\%, $P<0.05)$, but this was not significant for boys alone $(P=0 \cdot 27)$. Otherwise, food sources did not differ substantially or consist- 


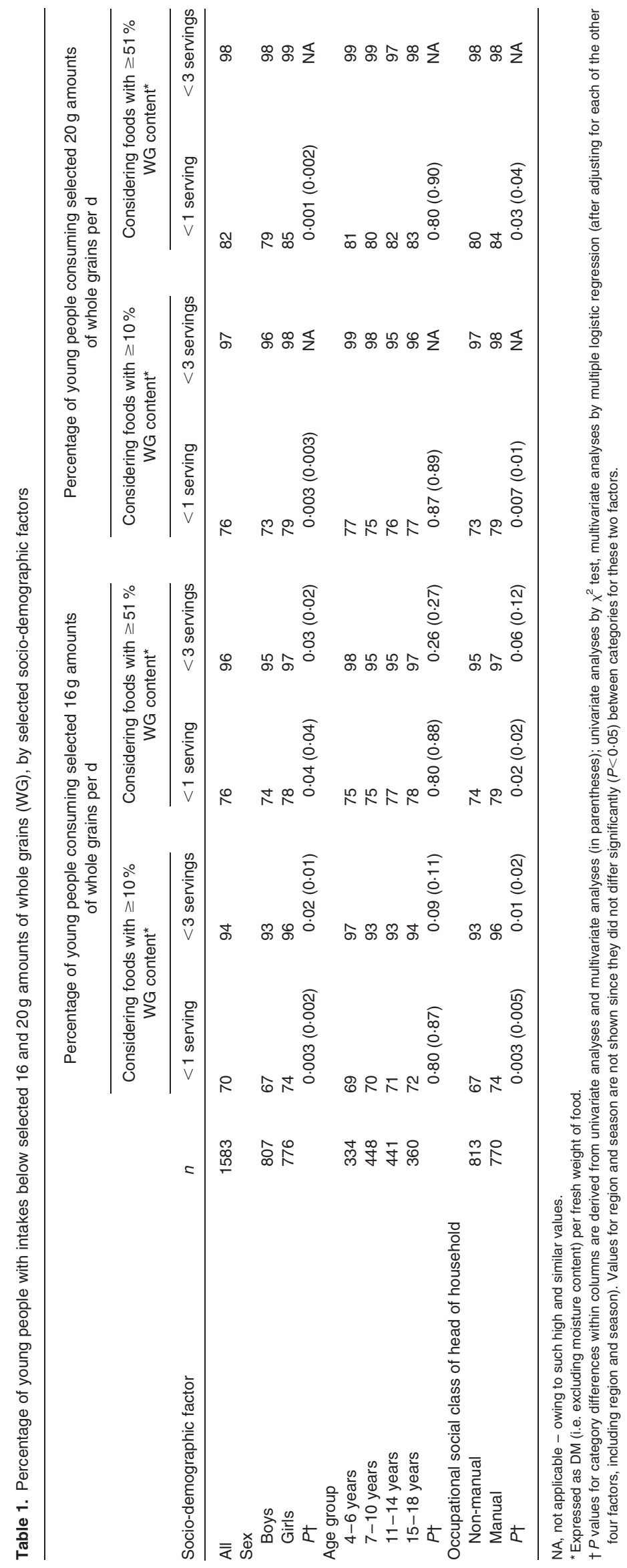




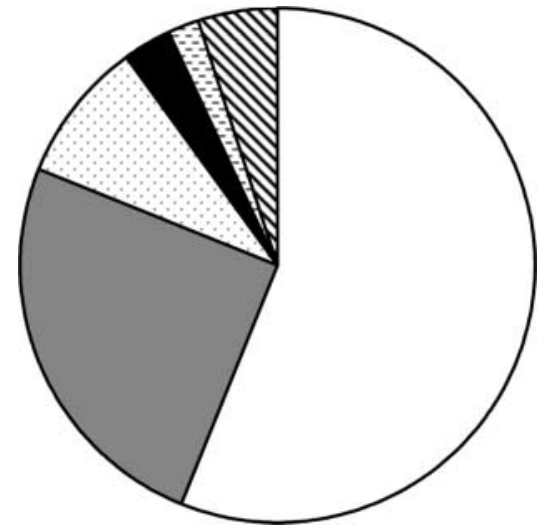

Fig. 1. Food sources of whole-grain intake among young people aged 4-18 years ( $n$ 1583) ( $\square$, breakfast cereals; $\square$, breads (mainly wholemeal); 䛜, biscuits; $\square$, pasta, rice, pizza and other cereals; 圆, buns, cakes, pastries and fruit pies; $\mathbb{\nabla}$, other foods (includes popcorn, cereal-based puddings and savoury snacks)

ently with sex, age group, region, season or occupational social class of head of household. In addition, sources of whole-grain intake did not vary significantly after excluding those who reported being unwell with eating habits affected or likely under-reporters.

Almost one-half (47\%) of the young people aged 4-18 years consumed no whole-grain-containing breakfast cereals, and over three-quarters $(76 \%)$ consumed no wholemeal bread, over the $7 \mathrm{~d}$ period of assessment. The percentage of non-consumers of wholegrain-containing breakfast cereals increased with age $(37,43,48$ and $59 \%$ for those aged $4-6,7-10,11-14$ and $15-18$ years, respectively; $P<0.001$, linear trend), but there was no age trend for wholemeal bread consumption. The percentage of non-consumers of each food source of whole-grain intake did not vary significantly with any of the other socio-demographic factors.

\section{Non-consumers of whole-grain foods}

Over one-quarter $(27 \%)$ of all young people consumed no foods with $\geq 10 \%$ whole-grain content during the $7 \mathrm{~d}$ period of dietary assessment. When whole-grain intake was estimated from wholegrain foods with $\geq 51 \%$ whole-grain content only, $41 \%$ of young people were found to have no intake (Table 2).

Although the percentage of young people with no whole-grain intake did not differ significantly by sex, it was significantly higher with age group and among those whose head of household had a manual versus non-manual occupation, independent of the other socio-demographic factors. These percentages were not altered significantly after excluding those who reported being unwell with eating habits affected or after additional exclusion of likely under-reporters.

Young people whose head of household was in a manual compared with non-manual occupation were $49 \%(95 \%$ CI 27,71$)$ more likely to be identified as non-consumers of whole grains. Differences in whole-grain intake by occupational social class of head of household were greatest among young people aged 11-18 years, as shown in Fig. 2.

\section{Discussion}

The present study demonstrates, for the first time, that the consumption of whole-grain-containing foods by young people in
Table 2. Percentage of young people with no whole-grain (WG) intake, by selected socio-demographic factors

\begin{tabular}{|c|c|c|c|}
\hline Socio-demographic factor & $n$ & $\begin{array}{c}\text { Considering foods } \\
\text { with } \geq 10 \% \\
\text { WG content }\end{array}$ & $\begin{array}{c}\text { Considering foods } \\
\text { with } \geq 51 \% \\
\text { WG content }\end{array}$ \\
\hline All & 1583 & 27 & 41 \\
\hline \multicolumn{4}{|l|}{ Sex } \\
\hline Boys & 807 & 28 & 41 \\
\hline Girls & 776 & 27 & 40 \\
\hline$P+$ & & $\begin{array}{c}0.80 \\
(0.75)\end{array}$ & $\begin{array}{c}0.82 \\
(0 \cdot 77)\end{array}$ \\
\hline \multicolumn{4}{|l|}{ Age group } \\
\hline $4-6$ years & 334 & 23 & 31 \\
\hline $7-10$ years & 448 & 25 & 38 \\
\hline $11-14$ years & 441 & 29 & 45 \\
\hline $15-18$ years & 360 & 34 & 47 \\
\hline$P+$ & & $\begin{array}{l}0.007 \\
(0.008)\end{array}$ & $\begin{array}{l}<0.001 \\
(<0.001)\end{array}$ \\
\hline \multicolumn{4}{|l|}{$\begin{array}{l}\text { Occupational social class } \\
\text { of head of household }\end{array}$} \\
\hline Non-manual & 813 & 24 & 38 \\
\hline Manual & 770 & 32 & 44 \\
\hline$P+$ & & $\begin{array}{l}<0.001 \\
(0.001)\end{array}$ & $\begin{array}{c}0.01 \\
(0.02)\end{array}$ \\
\hline
\end{tabular}

* Expressed as DM (i.e. excluding moisture content) per fresh weight of food.

$\dagger P$ values for category differences within columns are derived from univariate and multivariate analyses (in parentheses); univariate analyses by $\chi^{2}$ test, multivariate analyses by multiple logistic regression (after adjusting for each of the other four factors, including region and season). Values for region and season are not shown since they did not differ significantly $(P<0.05)$ between categories for these two factors.

Great Britain is very low, with a median whole-grain intake of just $7 \mathrm{~g} / \mathrm{d}$. There was no whole-grain intake by $27 \%$ of participants during the survey period. The low whole-grain intake of the present study is consistent with that reported in the USA, among young people (Albertson \& Tobelmann, 1995; Kantor et al. 2001; Harnack et al. 2003) and adults (Cleveland et al. 2000), and among British adults (Lang et al. 2003). The finding that greater consumption of whole grains tended to be associated with higher socio-economic status of the household is also consistent with previous reports in Great Britain (Lang et al. 2003) and in the USA (Cleveland et al. 2000; Harnack et al. 2003).

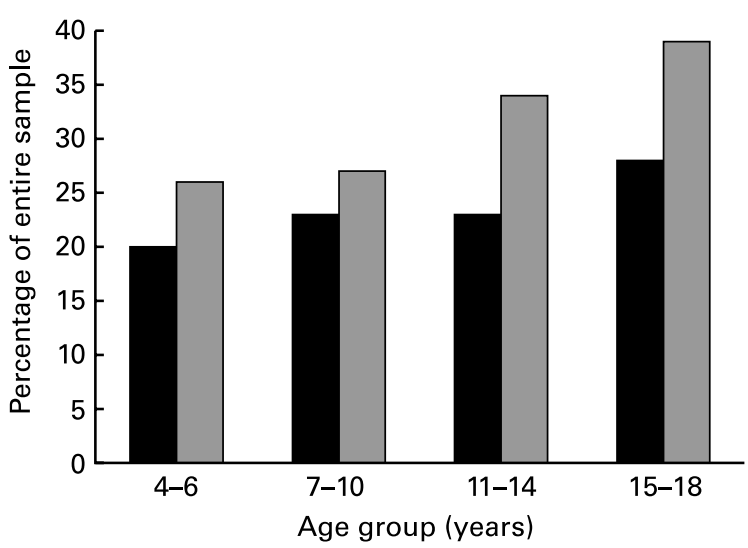

Fig. 2. Percentage of young people with no whole-grain intake, by age group and occupational social class of head of household ( $\mathbf{\square}$, non-manual; $\mathbf{\square}$, manual). Sample sizes (by non-manual and manual social class of head of household) for the four age groups were as follows: 4-6 years, $n 174$ and $160 ; 7-10$ years, $n 239$ and $209 ; 11-14$ years, $n 213$ and 228; $15-18$ years, $n 187$ and 173 
When findings from the current analysis are extrapolated to the wider population of young people living in the UK, it should be remembered that those aged 15-18 years and from families where the head of household had a manual occupation will have been under-represented. Since whole-grain intake among these two socio-demographic categories tended to be lower than among other categories of the same variables, whole-grain intake among the wider population of young people is probably even lower than that reported herein.

Absolute intakes of whole grains are not easy to compare since previous surveys of young people used servings of whole-grain foods or eating occasions, and used different methodologies and durations for dietary assessment. However, data from the 19946 Continuing Survey of Food Intake by Individuals, obtained by dietary recall over two non-consecutive days, shows that wholegrain intake among American young people has been found to be well below the recommendation for whole-grain food consumption (US Department of Health and Human Services and US Department of Agriculture, 2005), at $\leq 1$ serving/d among children aged 2-18 years (Harnack et al. 2003). The percentage of the American young people who consumed no whole-grain servings was 20 , with the percentage increasing with age $(2-5$ years, $13 \%$; 6-11 years, $15 \%$; $12-18$ years, $27 \%$ ). Two-thirds consumed $<1$ daily serving of whole grains, while $9 \%$ of young people aged $2-19$ years consumed $\geq 3$ whole-grain servings/d (Kantor et al. 2001).

The major sources of whole-grain intake in these British young people were breakfast cereals $(56 \%)$ and bread $(25 \%)$, with modest contributions from biscuits $(9 \%)$. However, one-half consumed no whole-grain-containing breakfast cereal and three-quarters no wholemeal bread. In American young people, breakfast cereals have been found to contribute most $(38 \%)$ to wholegrain intake, although this proportion is much lower than in the NDNS, mainly because corn and other chips (providing 22\%) were also included as a whole-grain food. American young people derived $18 \%$ of their whole grains from yeast breads and substantially more from popcorn (9\%; Harnack et al. 2003) than those living in Great Britain.

Food sources of whole-grain intake in the NDNS young people were slightly different to those reported (Lang et al. 2003) from analysis of data of British adults from the 1986-7 Dietary and Nutritional Survey of British Adults (Gregory et al. 1990) and the 1994-5 NDNS of people aged 65 years and over (Finch et al. 1998), notwithstanding the differences in methodology. Breakfast cereals contributed more to whole-grain intake in young people than to consumption occurrences of whole-grain foods in adults $(56 \%$ v. $34 \% ; P<0.001)$ while the contribution from wholemeal bread was significantly lower $(21 \%$ v. $46 \%$; $P<0.001)$.

The decline in the contribution of breakfast cereals to wholegrain intake with age was due not only to a reduction in frequency of consumption of whole-grain breakfast cereals by consumers but also an increased percentage of non-consumers. It is noteworthy that around one-half of young people in the present study consumed no whole-grain breakfast cereals over the $7 \mathrm{~d}$ period of assessment, and that this proportion increased significantly with age. In particular, girls aged 15-18 years in the present study derived the lowest percentage of their whole-grain intake from breakfast cereals. This may partly be attributed to under-reporting but may also have been due to the skipping of breakfast that tends to become more prevalent in later adolescence, particularly among girls - often linked to attempts at weight control (Lattimore \& Halford, 2004).

Although most of the results from the present analysis have been obtained using data from the entire sample, being unwell with eating habits affected and likely under-reporting have also been taken into account. Exclusion of the $10 \%$ of participants who reported being unwell with eating habits affected on at least 1 of the $7 \mathrm{~d}$ of dietary assessment had no significant impact on the conclusions. Similarly, our crude measure of under-reporting found that the differences observed in wholegrain intake by socio-demographic factors tended to remain although their size and significance were sometimes attenuated. Therefore, even if under-reporting has reduced the estimate of absolute whole-grain intake, the true intake is still likely to be low and not dissimilar to that given in this paper.

The decision to estimate whole-grain intake by considering consumption of all foods containing $\geq 10 \%$ rather than requiring higher amounts of whole-grain content raises an important issue. If only foods containing a higher percentage of whole grains, such as $\geq 51 \%$, were considered, overall intake would have been under-estimated by $28 \%$. If a lower cut-off point of wholegrain content of $25 \%$ had been used, whole-grain intake in the present study would still have been under-estimated by $15 \%$. In addition, there is likely to be an even greater under-estimate of true whole-grain intake among the youngest children and those whose head of household was of manual occupational social class, since they tended to have a greater consumption of foods containing $<51 \%$ whole-grain content.

We believe that the quantification of absolute intake of whole grains will provide a more robust basis on which to examine diet-disease associations. The first study to assess the link between quantified whole-grain intake and health outcomes has recently been published (Jensen et al. 2004). A significant inverse association was shown between whole-grain intake and 14-year risk of CHD, with each $20 \mathrm{~g}$ increment in whole-grain intake corresponding to a $6 \%(95 \%$ CI 0,13$)$ reduction in risk. In that study, whole-grain intake was calculated from dietary information collected with a validated semi-quantitative food frequency questionnaire, in contrast to $7 \mathrm{~d}$ weighed dietary records used in the present study.

Although the present study has focused only on foods containing the whole grain, benefits to health may also be obtained by consuming grains from which only a small proportion of the whole grain has been removed during processing. When consumed in large amounts, foods containing almost all of the whole grain may also confer health benefits. This underlines the need to establish a clearer mechanistic basis for the health effects currently attributed to 'whole-grain' foods.

It also needs to be clarified whether associations reported between higher whole-grain intake and improved health are due to the nutritional attributes of whole grains per se or whether whole grains act merely as a marker for a healthier diet and/or lifestyle. Although whole grains may contain many desirable nutrients and phytochemicals, high consumption of other healthful foods (e.g. fruit and vegetables), lower intake of less desirable dietary components (e.g. total and saturated fat) and lifestyle differences often accompany high whole-grain intake.

It is clear from the present study that the consumption of whole-grain foods by British young people is currently low. Further research is required to (1) define exactly what constitutes 
a whole-grain serving, (2) determine the level of whole-grain intake associated with health benefits, and (3) examine the impact of increased consumption of whole-grain foods, through controlled dietary intervention studies. Together, this should provide a more robust foundation on which to base dietary recommendations.

\section{Acknowledgements}

The present study was funded by Cereal Partners UK and the Medical Research Council. We also thank the UK Data Archive, University of Essex, Colchester for providing an electronic copy of the survey dataset and for granting permission for this analysis.

\section{References}

Albertson AM \& Tobelmann RC (1995) Consumption of grain and wholegrain foods by an American population during the years 1990 to 1992. J Am Diet Assoc 95, 703-704.

Anderson JW (2003) Whole grains protect against atherosclerotic cardiovascular disease. Proc Nutr Soc 62, 135-142.

Cleveland LE, Moshfegh AJ, Albertson AM \& Goldman JD (2000) Dietary intake of whole grains. $J$ Am Coll Nutr 19, S331-S338.

Finch S, Doyle W, Lowe C, Bates CJ, Prentice A, Smithers G \& Clarke P (1998) National Diet and Nutrition Survey: People Aged 65 Years and Over, vol. 1. Report of the Diet and Nutrition Survey. London: The Stationery Office.

Food Standards Agency (2002) McCance and Widdowson's The Composition of Foods, 6th summary ed. Cambridge: Royal Society of Chemistry.

Goldberg GR, Black AE, Jebb SA, Cole TJ, Murgatroyd PR, Coward WA \& Prentice AM (1991) Critical evaluation of energy intake data using fundamental principles of energy physiology: 1. Derivation of cut-off limits to identify under-reporting. Eur J Clin Nutr 45, 569-581.

Great Britain Office of Population Censuses and Surveys (1991) Standard Occupational Classifications, vol. 3. Social Classifications and Coding Methodology. London: Her Majesty's Stationery Office.

Gregory J, Foster K, Tyler H \& Wiseman M (1990) Dietary and Nutritional Survey of British Adults. London: Her Majesty's Stationery Office.

Gregory J, Lowe S, Bates CJ, Prentice A, Jackson LV, Smithers G, Wenlock R \& Farron M (2000) National Diet and Nutrition Survey: Young People Aged 4 to 18 Years, vol. 1. Report of the Diet and Nutrition Survey. London: The Stationery Office.

Harnack L, Walters SH \& Jacobs DR Jr (2003) Dietary intake and food sources of whole grains among US children and adolescents: data from the 1994-1996 Continuing Survey of Food Intakes by Individuals. J Am Diet Assoc 103, 1015-1019.

Hobson W (2002) The Classic 1000 Cake \& Bake Recipes. London: Foulsham

Holland B, Unwin ID \& Buss DH (1988) Cereals and Cereal Products. Third Supplement to McCance and Widdowson's The Composition of Foods. London: Royal Society of Chemistry/Ministry of Agriculture, Fisheries and Food.
Holland B, Welch AA, Unwin ID, Buss DH, Paul AA \& Southgate DAT (1991) McCance and Widdowson's The Composition of Foods, 5th ed. London: Royal Society of Chemistry/Ministry of Agriculture, Fisheries and Food.

Jacobs DR Jr \& Gallaher DD (2004) Whole grain intake and cardiovascular disease: a review. Curr Atheroscler Rep 6, 415-423.

Jacobs DR Jr, Marquart L, Slavin J \& Kushi LH (1998) Whole-grain intake and cancer: an expanded review and meta-analysis. Nutr Cancer 30, 85-96.

Jacobs DR Jr, Meyer HE \& Solvoll K (2001) Reduced mortality among whole grain bread eaters in men and women in the Norwegian County Study. Eur J Clin Nutr 55, 137-143.

Jacobs DR Jr, Meyer KA, Kushi LH \& Folsom AR (1999) Is wholegrain intake associated with reduced total and cause-specific death rates in older women: the Iowa Women's Health Study. Am J Public Health 89, 322-329.

Jensen MK, Koh-Bannerjee P, Hu FB, Franz M, Sampson L, Grønbæk M \& Rimm EB (2004) Intakes of whole grains, bran, and germ and the risk of coronary heart disease in men. Am J Clin Nutr 80, $1492-1499$.

Jones AR, Grimshaw RH, Richardson DP \& Seal CJ (2003) How much is enough? Estimates of portion sizes of wholegrain foods. Proc Nutr Soc 62, 54A.

Kantor LS, Variyam JN, Allshouse JE, Putnam JJ \& Biing-Hwan L (2001) Choose a variety of grains daily, especially whole grains: a challenge for consumers. J Nutr 131, S473-S486.

Lang R, Thane CW, Bolton-Smith C \& Jebb SA (2003) Consumption of whole-grain foods by British adults: findings from further analysis of two national dietary surveys. Public Health Nutr 6, 479-484.

Lattimore PJ \& Halford JCG (2004) Adolescence and the diet-dieting disparity: healthy food choice or risky health behaviour? Br J Health Psychol $\mathbf{8}, 451-463$.

Liu S, Willett WC, Manson JE, Hu FB, Rosner B \& Colditz G (2003) Relation between changes in intakes of dietary fiber and grain products and changes in weight and development of obesity among middle-aged women. Am J Clin Nutr 78, 920-927.

Paul AA \& Southgate DAT (1985) McCance and Widdowson's The Composition of Foods, 4th rev. ed. London: Her Majesty's Stationery Office.

Richardson DP (2003) Wholegrain health claims in Europe. Proc Nutr Soc 62, 161-169.

Schofield WN, Schofield C \& James WPT (1985) Basal metabolic rate. Hum Nutr Clin Nutr 39C, Suppl. 1, 1-96.

Slavin J (2003) Why whole grains are protective: biological mechanisms. Proc Nutr Soc 62, 129-134.

Smith AT, Kuznesof S, Richardson DP \& Seal CJ (in press) Tracking change in whole grain consumption using 'The Whole Grain Unit'. Public Health Nutr.

US Department of Health and Human Services and US Department of Agriculture (2005) Dietary Guidelines for Americans, 2005, 6th ed. Washington, DC: US Government Printing Office.

Venn BJ \& Mann JI (2004) Cereal grains, legumes and diabetes. Eur J Clin Nutr 58, 1443-1461. 